\title{
A organização escolar em ciclos e a questão da igualdade substantiva
}

\author{
Marília Gouvea de Miranda \\ Universidade Federal de Goiás, Faculdade de Educação
}

\section{Introdução}

No conjunto de reformas por que vem passando a educação brasileira, há uma tendência em substituir, no ensino público, a organização escolar em séries por ciclos: ciclos de formação, de aprendizagem, de desenvolvimento, de progressão continuada. Essa tendência, com suas especificidades, está também presente em reformas realizadas em outros países como Espanha, França, Bélgica, Canadá, Suíça. Ainda que no Brasil tenham existido experiências isoladas que receberam outras denominações, somente na década de 1980 a palavra ciclo passou a designar um modo de organização escolar oposto ao seriado. Com a Lei de Diretrizes e Bases da Educação Nacional (LDB, lei n. 9.394/96), tornaram-se possíveis numerosas iniciativas sistemáticas de organização escolar nessa modalidade, com proposições diferenciadas, em várias redes municipais e estaduais de ensino. Nessas propostas, a argumentação em defesa dos ciclos esteve sempre vinculada à necessidade de solucionar a grave questão da reprovação na educação pública brasileira. Na rede de ensino privada, em que os índices de reprovação são menos expressivos, essas iniciativas encontram menor ressonância.
Vários estudos têm discutido as questões relativas ao delineamento e às implicações dessas propostas (Barretto \& Sousa, 2004, 2005; Freitas, 2003; Franco, 2004; Mainardes, 2007, para citar alguns) e não se pretende abordar esses aspectos. A finalidade do presente artigo é retomar uma questão já esboçada em texto anterior (Miranda, 2005) acerca dos fundamentos da escola de ciclos, ou seja, por que razão a escola deve passar a se organizar em ciclos. Ou, perguntando de outro modo, em que se sustenta a justificação dessa modalidade de organização escolar? A que se destina?

Para abordar essa questão, será necessário antes discutir o sentido de escola organizada em ciclos. Perrenoud (2004, p. 35) propôs uma "definição mínima”, com ênfase na questão da avaliação: “um ciclo de aprendizagem é um ciclo de estudos no qual não há mais reprovação”. Com base nesse mínimo critério da ausência de reprovação, não haveria diferenciação entre as propostas de ciclos e as propostas que se limitam à progressão continuada, o que tem levado muitos autores dedicados ao tema a se preocupar em estabelecer uma distinção entre elas. Em um estudo sobre as políticas de ciclos no Brasil, Barretto e Sousa (2005, p. 660) propuseram-se a distinguir e ampliar 
a compreensão dessa modalidade de organização da escola quando assim a caracterizaram:

\begin{abstract}
Os ciclos [...] compreendem alternativas de organização do ensino básico, que ultrapassam a duração das séries anuais como referência temporal para o ensino e a aprendizagem e estão associados à intenção de assegurar à totalidade dos alunos a permanência na escola e um ensino de qualidade. Nesse sentido, eles têm a ver com o propósito de superar a fragmentação artificial do processo de aprendizagem ocasionada pela seriação, a qual tem levado a rupturas na trajetória escolar, uma vez que dá margem a reprovações anuais. Mas vão além, pois demarcam mudanças de concepção de conhecimento e de aprendizagem, na ocupação do tempo escolar, bem como na própria função da educação escolar, vindo a constituir um caminho potencial para a democratização do ensino.
\end{abstract}

Essa caracterização contém elementos importantes para a compreensão dos ciclos: o tempo de permanência do aluno na escola, a noção de ensino de qualidade, a contraposição ao regime seriado com seu sistema de aprovação e reprovação, as mudanças nas concepções de conhecimento e aprendizagem, na ocupação do tempo escolar e na concepção de função da escola e, ainda, a perspectiva de democratização do ensino.

Muitos desses aspectos têm sido reiterados em estudos publicados sobre a organização escolar em ciclos, que tendem a ser muito favoráveis à sua implantação. Mainardes (2007, p. 88), analisando 155 trabalhos (39 teses e dissertações, 11 livros, 41 capítulos de livros e 64 artigos) publicados entre 1987 e 2004, observou que "os textos classificados como comentários e críticas [...] oferecem poucos elementos para a compreensão crítica dessa política”. As críticas, quando ocorrem, estão direcionadas à análise dos problemas decorrentes da implantação das propostas, como o distanciamento entre o discurso oficial e a prática real, entre os dados estatísticos e a realidade da escola. Tende, assim, a prevalecer uma convergência na argumentação de que a organização escolar em ciclos é uma alternativa para combater o fracasso escolar, ao adequar os tempos e espaços escolares às necessidades de aprendizagem dos alunos da escola pública.

Contudo, os argumentos em defesa da escola de ciclos nem sempre explicitam claramente o conjunto de princípios de ordem teórica, prática, social, política, pedagógica e psicológica que os fundamenta. A produção referente às políticas de não-retenção no Brasil não tem se dedicado suficientemente à análise de seus pressupostos (Mainardes, 2007), o que reforça a necessidade de estudos teóricos mais sistemáticos. Neste artigo, pretende-se abordar alguns desses fundamentos e suas implicações, discutindo inicialmente a pertinência de aludir à psicologia como sua principal referência, passando à questão mais determinante, que é a compreensão dos sentidos atribuídos à educação escolar contemporânea: o embate entre o discurso liberal da igualdade, com suas variantes atuais em defesa das diferenças, e o princípio da igualdade substantiva.

\section{O aporte psicológico na organização escolar em ciclos}

Tem-se afirmado com frequência que a proposta de ciclos se fundamenta em princípios da psicologia. Afinal, algumas questões de ordem psicológica estariam sugeridas ou pressupostas nessa reforma: os critérios que orientam a noção de ciclos em suas diferentes nomenclaturas (aprendizagem; desenvolvimento; formação), as concepções de desenvolvimento e de aprendizagem, a atenção às necessidades individualizadas dos alunos e o problema da autoestima, entre outros. De fato, os estudos sobre a escola de ciclos referem-se a várias teorias psicológicas, com destaque para Vygotsky, Wallon e Piaget. Henry Wallon, coautor do famoso plano Langevin-Wallon (1977) de reforma da educação francesa de 1946-1947, é frequentemente citado como precursor da escola em ciclos de formação humana, ao prever a organização do ensino em três ciclos (Krug, 2002; Lima, 2002). São também comuns as menções a Vygotsky e ao seu conceito de "zona de desenvolvimento proximal”, como aparece, por exemplo, em Krug (2002) e Teixeira (2004). 
A referência aos aportes psicológicos das propostas de ciclos vem acompanhada por uma justificável preocupação com os riscos de uma possível psicologização. ${ }^{1}$ Afinal, se é verdade que muitos consideram, ou pelo menos não recusam, a ideia de que as teorias psicológicas possam contribuir para a compreensão dos ciclos (de vida, de aprendizagem, de formação, de desenvolvimento), é necessário arguir a psicologia que se apresenta como fundamento acerca de como têm sido abordados os enfoques psicológicos na produção teórica sobre ciclos.

Numa pesquisa bibliográfica em que se perguntava como a psicologia tem sido referendada nos trabalhos sobre a escola organizada em ciclos, na condição de fundamento teórico para essa reforma educacional, foi feito um levantamento de artigos sobre esse tema em periódicos e eventos relevantes da área de educação no Brasil no período de 2000 a $2005 .{ }^{2}$

A definição do início do período decorreu do interesse em investigar trabalhos publicados após a implantação das reformas em curso. Foram selecionados periódicos com base em sua expressividade nacional e em seu conceito junto à Qualis da CAPES/ MEC: Educação e Sociedade; Revista Brasileira de Educação; Educação e Pesquisa e Cadernos de Pesquisa. Diante do pequeno número de artigos referentes

${ }^{1}$ Freitas (2003, p. 55), por exemplo, indica a necessidade de expandir a noção psicológica de desenvolvimento “adicionando um outro modo de conceber a dinâmica da formação do aluno que contrarie tanto a lógica da exclusão como da submissão”. Fundamentando-se no pedagogo russo Pistrak, Freitas lembra que, para além da abordagem psicológica do desenvolvimento, há também “o lado social da formação”. Barretto e Sousa (2005, p. 662), por sua vez, reconhecem uma aparente correspondência entre as idades da vida e a organização do sistema escolar, mas lembram que os ciclos não são fenômenos aos quais se possa atribuir um caráter meramente biopsicológico, pois eles são, sobretudo, “fruto de um processo de construção histórico-social”.

${ }^{2}$ Levantamento bibliográfico realizado sob minha orientação pela bolsista Mila Belíssimo Antonio José (PIBIC - Conselho Nacional de Desenvolvimento Científico e Tecnológico - CNPq/UCG). ao tema encontrado nesses periódicos, decidiu-se investigar também os trabalhos apresentados em eventos no mesmo período, por entender que esses são espaços importantes de divulgação de pesquisas educacionais em curso. Foram definidos dois eventos nacionais do campo da educação por sua relevância na área: as reuniões anuais da Associação Nacional de Pós-Graduação em Educação (ANPEd) e os eventos bienais do Encontro Nacional de Didática e Prática de Ensino (ENDIPE).

Os 87 trabalhos selecionados (13 provenientes de periódicos e 74, de eventos) foram distribuídos conforme demonstram os Quadros 1 e 2. No período estudado, o número de artigos publicados acerca da temática tendeu a se concentrar em 2004 e 2005. Nos anais dos eventos havia um número bem maior de trabalhos apresentados, indicando a mesma tendência ao incremento nos dois últimos anos. Predominaram os relatos de pesquisas realizadas nas redes públicas de ensino que adotaram a organização em ciclos, enfocando temas variados, com ênfase nas abordagens metodológicas do tipo estudo de caso e estudo de representações de professores e alunos.

A leitura dos trabalhos selecionados buscou identificar aqueles que se referem aos aspectos psicológicos em sua argumentação sobre os ciclos, incluindo a simples menção a um autor, a uma concepção teórica ou a um tema vinculado à psicologia. Os quadros seguintes permitem visualizar a distribuição desses trabalhos.

Quadro 1: Artigos em periódicos da área de educação com abordagem de escolas de ciclos (2000 a 2005), com foco na psicologia

\begin{tabular}{|l|c|c|c|}
\hline \multicolumn{1}{|c|}{ Periódicos } & Ano & $\begin{array}{c}\text { N. de artigos } \\
\text { selecionados }\end{array}$ & $\begin{array}{c}\text { N. de artigos } \\
\text { com foco na } \\
\text { psicologia }\end{array}$ \\
\hline Educação e Pesquisa & 2004 & 3 & - \\
\hline Cadernos de Pesquisa & 2005 & 3 & 1 \\
\hline Educação e Sociedade & 2005 & 1 & 1 \\
\hline \multirow{2}{*}{$\begin{array}{l}\text { Revista Brasileira de } \\
\text { Educação }\end{array}$} & 2000 & 1 & - \\
\cline { 2 - 4 } & 2003 & 1 & - \\
\cline { 2 - 4 } & 2004 & 4 & 2 \\
\hline \multicolumn{1}{|c|}{ TOTAL } & - & 13 & - \\
\hline
\end{tabular}


Quadro 2: Trabalhos em anais de eventos na área da educação com abordagem de escolas de ciclos (2000 a 2005), com foco na psicologia

\begin{tabular}{|c|c|c|c|}
\hline Anais & Ano & $\begin{array}{l}\text { N. de artigos } \\
\text { selecionados }\end{array}$ & $\begin{array}{l}\text { N. de artigos } \\
\text { com foco na } \\
\text { psicologia }\end{array}$ \\
\hline \multirow{6}{*}{$\begin{array}{l}\text { Reuniões Anuais da } \\
\text { ANPEd }\end{array}$} & 2000 & 5 & 4 \\
\hline & 2001 & 6 & 2 \\
\hline & 2002 & 2 & - \\
\hline & 2003 & 6 & 1 \\
\hline & 2004 & 9 & 2 \\
\hline & 2005 & 12 & 4 \\
\hline \multirow{2}{*}{$\begin{array}{l}\text { Encontros Nacionais de } \\
\text { Didática e Prática de } \\
\text { Ensino }\end{array}$} & 2002 & 14 & 4 \\
\hline & 2004 & 20 & 1 \\
\hline TOTAL & - & 74 & 18 \\
\hline
\end{tabular}

Poucos artigos (15\%) e trabalhos em eventos (24\%) da amostra selecionada fizeram alguma referência ao campo da psicologia. Considerando-se que em muitos desses trabalhos a vinculação com a psicologia mostrou-se muito tênue, esses percentuais sugerem que o debate acadêmico sobre o tema tem-se ocupado pouco em discutir a base psicológica das propostas de ciclos. ${ }^{3}$ Apenas nove dos vinte trabalhos selecionados fazem menção direta aos teóricos da psicologia no decorrer do texto ou nas referências bibliográficas, sendo que os psicólogos são referenciados na bibliografia somente em quatro trabalhos; três trabalhos se apoiam em comentadores e dois referenciam obras de psicologia na bibliografia, mas não as abordam no texto. Os principais autores citados foram Piaget, Vygotsky e Wallon, mas na maioria dos trabalhos suas teorias não mereceram estudo aprofundado. Em geral, quando apareceram temas, autores ou teorias vinculados a essa ciência, isso ocorreu por meio de breves registros de estudos vinculados às psicologias do desenvolvimento

3 Também Mainardes (2007), em uma revisão da literatura já citada, identificou seis trabalhos que abordavam "aspectos psicológicos” dentre os 155 textos publicados no Brasil no período de 1987 a 2004. Uma revisão sobre pesquisas mais recentes sobre a organização da escolaridade em ciclos no Brasil pode ser encontrada no artigo de Mainardes neste número da Revista Brasileira de Educação. e da aprendizagem ou mais diretamente a algum dos autores já mencionados.

As implicações psicológicas não teriam sido, assim, tratadas como uma mediação significativa para a compreensão e justificação das políticas de organização escolar em ciclos. Os fundamentos psicológicos, explícitos ou implícitos, estariam subordinados a explicações de outra ordem, sendo eles mais determinantes e imprescindíveis na justificação da escola de ciclos. Quais seriam esses princípios que se sobreporiam aos preceitos psicológicos?

Em parte esses princípios já foram aqui indicados, quando se procurou introduzir a noção de uma escola organizada em ciclos que se insurge como uma contraposição à fragmentação artificial dos processos de aprendizagem. Isso implica mudanças na organização dos tempos e espaços escolares e, por sua vez, repõe a discussão acerca dos sentidos de uma escola que se pretende democrática. Esse parece ser o princípio fundamental da escola de ciclos: para distinguir-se da progressão continuada (a mesma escola que aí está, com a diferença de que os alunos não seriam retidos), a proposta de ciclos precisa agregar um novo sentido de escola ao critério de não-retenção. O que deve então mudar é a escola. Mas, se é assim, qual é o princípio que orienta essa mudança na perspectiva da escola de ciclos?

\section{O princípio da socialidade na escola de ciclos}

A mudança do sentido de escola nas propostas de ciclos é orientada pelo entendimento de que ela deva combater as desigualdades sociais, em particular aquelas que afetam a escola como instância de mediação das desigualdades. Afinal, a proposta de ciclos pretende corrigir ou minorar os desacertos dessa escola graduada por idade (ano de vida - ano de escola) ao buscar assegurar a permanência da criança em períodos mais extensos e mais flexíveis na escola de ciclos (ciclo da vida - ciclo escolar).

Em estudo anterior (Miranda, 2005), essa alteração de fundo no modo de conceber a escola foi caracterizada como uma mudança de princípios: deixa de orientar-se predominantemente por uma lógica 
vinculada aos processos de aquisição do conhecimento e suas amarras de retenção (princípio do conhecimento) para orientar-se por outra lógica fundada em um princípio da socialidade, o qual propõe que a escola deva ser uma instância cuja finalidade precípua seria efetivar-se como um espaço/tempo ao qual os alunos devam pertencer, flexibilizando ou suprimindo os fatores que promovem a retenção. ${ }^{4} \mathrm{O}$ termo socialidade foi empregado para se distinguir dos sentidos mais corriqueiros dos termos socialização, como processo de internalização mediado pela escola, ou de sociabilidade, relativa à disposição para convívio em sociedade. Socialidade demarcaria, assim, importante preceito da escola de ciclos, ênfase na noção de escola como espaço/tempo de convivência:

O importante é que os alunos permaneçam na escola, disponham de tempo e de espaço para que possam desfrutar o que ela possa lhes oferecer, inclusive a oportunidade de adquirir conhecimentos, mas não apenas isso ou não fundamentalmente isso: que eles possam viver ali e naquele momento uma experiência de cidadania, de convivência, de formação de valores sociais. (Miranda, 2005, p. 642)

Ao buscar remover os mecanismos de retenção que afastam as crianças e os jovens, a proposta de ciclos necessita imprimir um sentido diferenciado de escola, uma vez que a mera supressão da reprovação não assegura a efetividade do princípio da socialidade. Isso seria garantido por uma escola que, ao não mais permitir que o fluxo dos alunos seja retido, deva ser também capaz de contemplá-los não somente no sentido de uma "escolaridade igual”, mas de compreendêlos em sua individualidade, na perspectiva de uma escola orientada para a “diversidade” (Gimeno Sacristán, 2001). Ou seja, na medida em que os mecanismos de retenção deixem de operar seletivamente, os alunos,

\footnotetext{
${ }^{4}$ Para muitos não haveria contraposição de princípios, mas uma subordinação da lógica que rege a escola graduada aos preceitos da escola de ciclos. Com isso, a aquisição dos conhecimentos estaria assegurada na lógica dos ciclos, com a diferença de que não mais promoveria a retenção dos alunos.
}

reunidos pelo princípio da socialidade, precisam ser contemplados em suas diferenças, em sua diversidade. Afinal, se a suposta noção de unidade anteriormente tecida por uma ideia de organização escolar baseada no conhecimento desaparece, será preciso constituir outra unidade, agora sustentada pela noção de diversidade. Quais as implicações dessa mudança de concepção?

Assim, a discussão do sentido da escola proposto pela escola de ciclos não escapa de um debate contemporâneo importante que encontra suas raízes no processo de constituição da sociedade burguesa: o princípio da igualdade e as tentativas de removê-lo em nome do princípio da diferença, da diversidade.

\section{A crise da igualdade formal como princípio}

Diante do aprofundamento das desigualdades sociais, são repostos problemas importantes do debate contemporâneo sobre o princípio da igualdade. Como se sabe, esse princípio, que está na base do processo de constituição da escola no mundo moderno - a educação deve destinar-se a todos -, decorre do preceito liberal da igualdade entre os homens e está fadado a permanecer nessa sociedade como um princípio meramente formal.

Para compreender o sentido da igualdade no advento e na continuidade do mundo burguês, devese recordar, com Goldmann (1974, p. 29-30), que o primeiro princípio a ser ressaltado é, sem dúvida, o da liberdade, a primeira palavra da Declaração dos Direitos do Homem e do Cidadão, de 1789. A liberdade surgiu das lutas contra a ordem hierárquica do Antigo Regime como um ideal político: o homem livre nas cidades. A segunda noção é o individualismo, cuja dimensão de liberdade é elevada ao seu extremo: "o indivíduo é o homem liberado de todos os vínculos e limitado unicamente pela obrigação de respeitar a liberdade de seus semelhantes”. A terceira noção é a igualdade jurídica, porque o indivíduo só pode ser livre em uma sociedade sem privilégios. A quarta noção, fundamento de todas as outras, e que se pode acrescentar a essa tríade de Goldmann, é a defesa da propriedade, exigência histórica do modo de produção capitalista. 
Se os conceitos de igualdade e de liberdade estão perpassados pela ideia de propriedade, então as possibilidades de se efetivarem como princípio estão comprometidas desde a sua base. A sociedade que se firma no princípio formal da igualdade é, por excelência, uma sociedade caracterizada pelas desigualdades sociais que ela promove. O princípio presumido da igualdade é, portanto, muito caro às formas de organização econômica, social e política da sociedade capitalista, pelo menos enquanto princípio formal, ou seja, aquele que é estabelecido por todo o seu aparato legal. Esse formalismo jurídico implica uma série complexa de operações destinadas a delimitar e justificar as desigualdades baseadas na propriedade, na diferença sexual, na raça, enfim, "nos espaços de tensão impossíveis de solucionar pela via do acordo racional” (Ciriza, 2006).

As discussões travadas sobre esse tema pelos filósofos dos séculos XVII e XVIII mantêm a sua atualidade. Para Locke, a existência do indivíduo é anterior à sociedade e ao Estado. Os homens viviam originalmente em um estágio pré-social e pré-político, caracterizado pela mais perfeita liberdade e mais perfeita igualdade, chamado de estado de natureza. Nesse estado pacífico, os homens já eram dotados de razão e desfrutavam da propriedade: da vida, da liberdade e dos bens como direitos naturais do ser humano. Na condução natural, os homens viviam em estado de perfeita liberdade ("para ordenar-lhes as ações e regular-lhes as posses e as pessoas conforme acharem conveniente, dentro dos limites das leis da natureza, sem pedir permissão ou depender da vontade de qualquer outro homem” (Locke, 1983, p. 35) e de igualdade ("no qual é recíproco qualquer poder e jurisdição, ninguém tendo mais que qualquer outro”). Liberdade e igualdade são, portanto, para Locke, dois conceitos quase indiferenciados (Kuntz, 1998, p. 91).

Diferentemente de Hobbes, segundo o qual a propriedade foi instituída pelo Estado após a formação da sociedade civil, Locke compreende a propriedade privada como um direito natural do indivíduo, sendo portanto anterior à sociedade, e não podendo ser violado pelo Estado. O fundamento originário da proprie- dade, para Locke, é o trabalho. Para contraporem-se aos inconvenientes do estado de natureza, como a violação da propriedade (da vida, da liberdade, dos bens), os homens estabelecem livremente entre si o contrato social, que marca a passagem do estado de natureza para a sociedade política ou civil e tem como principal objetivo a preservação da propriedade e a proteção da comunidade.

A dificuldade de equacionar liberdade e desigualdade em uma sociedade de desiguais foi tratada por Rousseau de modo original. Após denunciar a fragilidade das leis e da sociedade civil perante a provocativa pergunta da Academia de Dijon acerca da origem das desigualdades entre os homens, no Contrato Social, Rousseau (1983a, p. 50) trata a igualdade como igualdade jurídica: “o pacto social estabelece entre os cidadãos uma tal igualdade que eles se comprometem todos nas mesmas condições e devem todos gozar dos mesmos direitos”. Sob o contrato social, as leis advindas da vontade geral, ao mesmo tempo em que buscam assegurar a liberdade e a igualdade, preservam o direito à propriedade.

Muito diversa é a posição de Aléxis de Tocqueville (1969) para a questão da desigualdade e da igualdade. Convencido da irremediável marcha da igualdade, a liberdade não poderia mais se fundamentar na desigualdade, como ocorria na aristocracia, passando a assentar-se sobre a realidade democrática da igualdade, como a que se desenvolvia nos Estados Unidos da América. Para Tocqueville, o que prevalece na democracia não é a igualdade entre os indivíduos ou a igualdade econômica, mas a igualdade de condições, no sentido de que as posições sociais são a todos acessíveis, o que implica uma tendência à uniformização dos modos e níveis de vida (Aron, 1987, p. 209).

Para Marx, do ponto de vista da lógica do desenvolvimento do capitalismo, a ideia de igualdade em causa, vinculada à de liberdade e de propriedade, é a igualdade de indivíduos “livres proprietários”, para que possam se encontrar no mercado como "personificação de relações econômicas”, iguais perante a lei, com garantia do contrato afiançado pelo direito que regula e controla essas relações. Contudo, concebido dessa 
forma, o preceito de igualdade (e também de liberdade) determinado pelo preceito de propriedade e contrato está definitivamente comprometido. Essa constatação não é apenas conceitual, mas estrutural e histórica. A sociedade que se firma no princípio formal da propriedade privada é, em seu fundamento, desigual.

Os desdobramentos do capitalismo que se seguiram confirmaram o aprofundamento das desigualdades sociais e a força do contrato social na preservação das condições da legitimação dos processos de exploração, com o agravante de que muitas das "escassas medidas de igualdade formal” passaram a ser consideradas "um luxo inacessível e anuladas sem cerimônia" (Mészáros, 2007, p. 186). A par disso, registrou-se, na última quadra do século XX, uma tendência à redefinição ou mesmo à supressão do princípio de igualdade, o que se expressa predominantemente (1) pela proposição de um “liberalismo igualitário”, que tende a substituir igualdade por equidade, e (2) pela defesa de um princípio da diversidade como crítica ao preceito da igualdade.

O liberalismo igualitário refere-se às teorias filosóficas sobre justiça, em especial, às ideias de John Rawls, em seu livro Teoria da justiça, de 1971, na defesa de uma "justiça como equidade" para as sociedades democráticas. Ele define dois princípios: pelo primeiro, direitos e liberdades deveriam ser tão extensos quanto possível para cada indivíduo; pelo segundo, o chamado "Princípio da Diferença”, as desigualdades sociais e econômicas deveriam ser ordenadas de modo a permitir, ao mesmo tempo, “o maior benefício possível para os menos favorecidos”, e a vinculação a posições e cargos acessíveis a todos "em condições de igualdade eqüitativa de oportunidades” (Rawls, 2002, p. 333). Em face do aprofundamento das desigualdades, são redobrados os esforços para justificar as políticas orientadas para a promoção da equidade e não mais da igualdade, e é desse modo que a ela se refere, nos dias atuais, a maior parte dos textos oficiais e acadêmicos.

Uma crítica ainda mais direta ao preceito da igualdade encontra-se nos autores que defendem a supressão desse princípio em benefício da noção de respeito à diversidade. O sociólogo François Dubet (2003), por exemplo, ao se confrontar com o fato inelutável do avanço das desigualdades sociais no mundo contemporâneo, ressalta que elas não apenas se mantiveram em patamares inaceitáveis como também se multiplicaram, identificando novas fontes de injustiça para além da dominação de classe, como aquelas que afetam as minorias e atingem grandes parcelas da população.

Dubet distingue na tradição sociológica duas grandes faces na afirmação da questão da igualdade/desigualdade: a "igualdade democrática” (tocquevilliana), a aspiração à igualdade dos indivíduos como um princípio que se afirma a despeito das desigualdades sociais reais; e as "desigualdades capitalistas", fundamentadas na interpretação de Marx, para quem as desigualdades de classe são estruturais e essenciais à historicidade e aos mecanismos de acumulação do capital.

Cético com relação às possibilidades interpretativas da crítica marxiana à sociedade capitalista nos dias atuais e convencido de que as multiplicidades das desigualdades e suas múltiplas causas recolocam o problema das desigualdades justas, Dubet (2003, p. 5) propõe "a única síntese ou conciliação possível” das duas faces da igualdade, que passa pelo reconhecimento do tema das identidades: os atores "querem, ao mesmo tempo, que a diversidade dos indivíduos seja reconhecida e que as desigualdades sejam justas”. Na medida em que a contradição entre os dois eixos da igualdade mostra-se mais aguda e violenta na atualidade, o sociólogo identifica na "obrigação de ser livre como condição de igualdade" a exposição dos indivíduos a uma série de "provações subjetivas", exemplificadas como a consciência infeliz, o desprezo, o retraimento e a violência (Dubet, 2003, p. 54 e passim).

Para enfrentar a questão das desigualdades justas nas escolas, Dubet (2003; e, principalmente, 2008) recorre às proposições de Rawls, ao propor a "igualdade individual das oportunidades”:

Além dos conhecimentos, das competências e de sua utilidade social, a escola produz um bem educativo particular que é a 
formação dos indivíduos como sujeitos capazes de dominar sua vida, de construir suas capacidades subjetivas de confiança em si e de confiança em outrem. Essa aprendizagem resulta menos dos saberes adquiridos que do seu modo de transmissão e do estilo educativo escolhido pela escola. Não somente uma escola justa deve ser útil à integração social dos alunos, mas ela deve formar os sujeitos de uma sociedade democrática e solidária. É nesse sentido que é preciso entender a igualdade individual das oportunidades. (Dubet, 2008, p. 95)

Contrapondo-se, ainda que parcialmente, ao princípio da igualdade meritocrática das oportunidades, que Dubet (2008) assimila ao princípio de igualdade, espera-se que a igualdade individual das oportunidades proteja os indivíduos do rigor e da violência dos processos de valorização do mérito e possa provê-los de uma imagem positiva de si mesmo. Para o autor, parece não haver contradição na proposição de que seria possível formar sujeitos para uma sociedade democrática e solidária por intermédio de um critério orientado para o bom proveito das "oportunidades" que são oferecidos aos indivíduos na escola.

Dubet aposta na construção das identidades individuais como perspectiva de confirmação das desigualdades justas e, em consequência, como estratégia de enfrentamento das desigualdades injustas. Isso é assumido como uma conciliação entre as duas faces da igualdade, o que faz recair sobre o indivíduo a tarefa de produzir uma síntese pessoal em meio às multiplicidades de diversidades que o constituem. Deve-se observar que, nessa "conciliação", a defesa liberal da igualdade individual sobrepõe-se a toda e qualquer discussão que implique a crítica aos fundamentos da sociedade capitalista e a consideração de uma ordem social alternativa.

István Mészáros (2002, 2007), em contrapartida, tem sido insistente na defesa da questão da igualdade substancial de todos os seres humanos como contraponto ao princípio da igualdade formal. ${ }^{5} \mathrm{O}$ autor está

${ }^{5}$ Wood (2003) e Callinicos (2003), em perspectivas diferenciadas, também discutem a abordagem contemporânea do conceito de igualdade e suas implicações em face do agravamento das desigualdades sociais e econômicas. convencido de que, sob as condições atuais, o controle sociometabólico do capital põe em risco não somente a vida humana mas a vida da natureza em nosso planeta. ${ }^{6}$ Nessa situação histórica, a questão da igualdade real ou substantiva deve ser reposta, porque se trata de "um traço necessário da definição positiva da ordem sociorreprodutiva alternativa” (2007, p. 235), nos termos de uma ordem econômica organizada e controlada por "produtores associados", independentemente do tempo que isso possa levar.

Ao discutir a educação, suas possibilidades históricas e as tarefas imediatas a serem empreendidas para além do capital, Mészáros retoma o imperativo de uma cultura de igualdade substantiva em substituição à cultura da desigualdade dominante, na qual "os indivíduos internalizam sua 'posição social', resignando-se mais ou menos consensualmente à sua condição de subordinação àqueles que tomam decisões sobre sua atividade vital” (2007, p. 191). Em outro texto, ressalta que a igualdade substantiva só pode transformar-se em um princípio orientador geral "por meio da autotransformação da educação como o desenvolvimento contínuo da consciência socialista” (2007, p. 306).

Na perspectiva desse autor, os discursos apologéticos em defesa da "igualdade de oportunidades", da "imparcialidade" e da "justiça" se sustentam na supressão da verdadeira igualdade produzida pelas hierarquias estruturantes do sistema do capital, o que esvazia o sentido das "oportunidades” que se pretende oferecer. A causa histórica da emancipação das mulheres, por exemplo, está condicionada à afirmação de uma demanda por uma igualdade substantiva, que desafie diretamente "a autoridade do capital preva-

${ }^{6}$ Acerca da crise estrutural do capital, adverte Mészáros (2007, p. 227): “dada a urgência de um tempo histórico único em que a sobrevivência da humanidade está em jogo - sob a sombra da acumulação aparentemente incontrolável e da disposição das armas reais [...] da destruição em massa, como da usurpação devastadora da natureza pelo capital -, o gênero humano não pode arriscar-se a reincidir em uma ordem social cada vez mais destrutiva, como se tivéssemos à nossa disposição a infinidade do tempo antes que tenhamos de empreender uma ação corretiva”. 
lecente no 'macrocosmo' abrangente da sociedade e igualmente no 'microcosmo' da família nuclear” (Mészáros, 2002, p. 273). De modo inverso, reitera o autor, sustentar o mito da "igualdade de oportunidades" pode significar manter a desigualdade. Justificase, assim, a necessidade de empreender uma crítica radical ao funcionamento dessa sociedade que $a$ priori exclui as possibilidades de uma verdadeira igualdade.

\section{Igualdade substantiva como desafio para a escola de ciclos}

Até que ponto se pode vincular a questão da organização escolar em ciclos à crise da noção de igualdade, que se manifesta com a proposição de um "liberalismo igualitário" e com a defesa de um princípio da diversidade? Como foi sugerido, é imperativo que a escola de ciclos se converta em uma perspectiva alternativa de escola, sob pena de não conseguir se distinguir dos programas de avaliação continuada. Quais seriam os elementos mais importantes a serem destacados na distinção da escola organizada em ciclos da escola organizada em séries anuais?

Em primeiro lugar, a escola de ciclos irá se diferenciar por assegurar a permanência de alunos que antes seriam retidos nas turmas e, em consequência, tendendo a interromper a sua trajetória de escolarização. Isso implica o desafio de acolher alunos mais diversificados, pois já não são selecionados por um critério operado a cada final de ano, que fazia com que as turmas que seguiam adiante fossem um tanto mais homogêneas com relação às aquisições de aprendizagem. Nas inúmeras variedades de composição de turmas existentes nas propostas implantadas no Brasil, as turmas são organizadas mediante ciclos mais alongados que compreendem uma determinada faixa etária. Fora isso, não haveria qualquer outro parâmetro definidor da composição dessas turmas, o que significaria o acolhimento de todas as possíveis diferenças entre os alunos ali envolvidos: de raça, de sexo, de religião, de desenvolvimento intelectual, de aptidão motora e sensorial, de configuração familiar, para citar algumas. Por se tratar de escolas públicas, o pertencimento a uma determinada classe social não seria uma "diferença”, mas um atributo comum senão a todos os alunos, pelo menos a quase todos.

Em segundo lugar, a escola de ciclos se configuraria uma situação em que o direito à escola estaria mais bem assegurado, pois o acesso e a permanência seriam garantidos a todos os alunos, não importando suas diferenças. Em outras palavras, ninguém deixaria de entrar e permanecer na escola por ser diferente, inclusive naquele sentido antes produzido pela própria escola por meio de mecanismos de reprovação: o aluno atrasado em relação ao fluxo escolar regular. Desse modo, a escola seria mais democrática e justa, porque mais equitativa, ou seja, aberta ao reconhecimento das diferenças: não só as crianças teriam mais tempo para desenvolver suas potencialidades individuais como também poderiam compartilhar um ambiente menos restritivo e discriminativo em relação às suas diferenças.

Em terceiro lugar, a escola de ciclos teria melhores condições de enfrentar uma dramática limitação da escola organizada em séries, que avalia e seleciona os alunos ano a ano: a baixa autoestima dos alunos decorrente de sucessivos fracassos vividos e assimilados individualmente. A escola de ciclos possibilitaria que os alunos não mais se confrontassem com parâmetros tão demarcados e sistemáticos de retenção, e com isso teriam melhores oportunidades em seu desenvolvimento afetivo e social, ficando mais protegidos das "provações subjetivas" a que se referia Dubet, o que significaria a possibilidade de desenvolver uma imagem mais favorável de si. Nesse sentido, continuaria sendo atribuído ao indivíduo a responsabilidade subjetiva de produzir uma síntese sobre si mesmo, só que agora em condições menos adversas.

Esses três pontos - a atenção à diferença, o direito a uma escolarização mais equitativa e a perspectiva de fortalecer a autoestima dos alunos - são referendados pelas propostas de implantação da organização escolar em ciclos, ainda que não necessariamente sejam assim sintetizadas. Afinal, a força desses princípios decorre menos de uma propositura clara e intencional da parte de seus defensores e da literatura voltada para esse tema e mais de uma noção que estaria implícita nessa proposta 
de ciclos, que decorreria do imperativo de se diferenciar significativamente da escola organizada em séries: ela põe em causa a questão da diversidade dos alunos. Em consequência, a noção de uma educação democrática assimilada por ela precisará incorporar esse parâmetro.

Essa constatação nos reconduz à discussão da igualdade como preceito fundamental do mundo moderno, que poderia ser sintetizado por meio do embate entre o princípio da igualdade formal, com suas variantes neoliberais contemporâneas, e o princípio da igualdade substantiva. Pode-se dizer que ambas se defrontam em alguma medida com a questão das desigualdades sociais, mas os posicionamentos são opostos. A contraposição entre o liberalismo igualitário e as condições de igualdade real expressa (e por certo encobre) uma contradição candente numa sociedade que convive com um aprofundamento sem precedentes dos processos de exploração e de apartação sociais.

Perante desigualdades sociais tão avassaladoras e visíveis, o enfrentamento da questão parece se dividir entre o reconhecimento e a atenção com relação às diferenças e a defesa intransigente da igualdade substantiva como um princípio orientador geral, que não desconhece em momento algum a diversidade humana mas não identifica aí o fundamento das desigualdades sociais. Afinal, em nossa sociedade as diferenças são convertidas em desigualdades como um pretexto para a exploração e junto produzem a sua justificação. Como bem disse Marx (s.d., p. 69), “um negro é um negro. Apenas dentro de determinadas condições ele se torna um escravo".

Diante desse embate de princípios, a consequência mais importante refere-se às aspirações de mudança da sociedade que aí está. Nesse sentido, é importante retomar a discussão acerca das implicações das reformas educacionais em nossa sociedade, cujas determinações fundamentais são irreformáveis. Recorrendo mais uma vez a Mészáros:

[...] procurar margens de uma reforma sistêmica na própria estrutura do sistema do capital é uma contradição em termos. É por isso que é necessário romper com a lógica do capital se quisermos contemplar a criação de uma alternativa educacional significativamente diferente. (2007, p. 198, grifos do original)

Romper com essa lógica implica não abrir mão da defesa da igualdade substantiva como princípio. Esse preceito é fértil "porque se contrapõe, porque desmascara, porque não integra e porque, fundamentalmente, desafia a história e mantém as possibilidades e compromissos com a emancipação de cada um e de todos os homens e mulheres” (Miranda \& Resende, 2009). E isso se impõe como uma ação a ser empreendida no tempo presente, mesmo que as condições de igualdade substantiva ainda não estejam dadas. Nesse sentido, é urgente pensar a escola na perspectiva de um princípio de igualdade cuja síntese compreenda as diferenças, mas que seja sobretudo orientado pela certeza de que não se pode abrir mão de uma educação para todos em seu sentido pleno.

Em que medida as propostas e os estudos sobre os ciclos estariam identificados com essa ou com aquela noção de igualdade? Essa é uma questão essencial, com a qual este artigo se encerra, na certeza de que se trata de resposta que requer mais estudos e novos debates. As implicações dessa questão, contudo, já podem ser compreendidas: o enfrentamento das desigualdades por meio da educação escolar encontra seu limite nas contradições de uma sociedade que se constitui mediante a afirmação dessas desigualdades. Ainda assim, insiste-se na educação como mediação fundamental na perspectiva de construção de uma sociedade orientada pelo princípio da igualdade substantiva. As mudanças que empreendemos na educação estão sujeitas a essa determinação histórica; esse é, mais uma vez, o nosso desafio.

\section{Referências bibliográficas}

ARON, Raymond. As etapas do pensamento sociológico. 2. ed. São Paulo: Martins Fontes, 1987.

BARRETTO, Elba Siqueira de Sá; SOUSA, Sandra Zákia. Estudos sobre ciclos e progressão escolar no Brasil: uma revisão. Educação e Pesquisa, São Paulo, v. 30, n. 1, p. 31-50, jan./abr. 2004. . Reflexões sobre as políticas de ciclos no Brasil. Cadernos de Pesquisa, São Paulo, v. 35, n. 126, p. 659-688, set./dez. 2005. 
CALLINICOS, Alex. Igualdad. Madrid: Siglo XXI, 2003. CIRIZA, Alejandra. A propósito de Jean Jacques Rousseau: contrato, educação, subjetividade. In: BORON, Atilio A. Filosofia política moderna. De Hobbes a Marx. Buenos Aires/São Paulo: CLACSO/ DCP-FFLCH/USP, 2006. Disponível em: <http://sala.clacso.org. ar/gsdl/cgi-bin/library>. Acesso em: 5 maio 2008. DUBET, François. As desigualdades multiplicadas. Ijuí: UNIJUÍ, 2003.

O que é uma escola justa? A escola das oportunidades. São Paulo: Cortez, 2008.

FRANCO, Creso. Ciclos e letramento na fase inicial do ensino fundamental. Revista Brasileira de Educação, n. 25, p. 30-38, jan./abr. 2004.

FREITAS, Luiz Carlos de. Ciclos, seriação e avaliação: confronto de lógicas. São Paulo: Moderna, 2003.

GIMENO SACRISTÁN, José. Educação obrigatória: seu sentido educativo e social. Porto Alegre: Artmed, 2001.

GOLDMANN, Lucian. Introdução à filosofia de Kant. Buenos Aires: Amorrortu, 1974.

KRUG, Andréa. Ciclos de formação: uma proposta transformadora. Porto Alegre: Mediação, 2002.

KUNTZ, Rolf N. Locke: liberdade, igualdade e propriedade. In: QUIRINO, Célia G.; VOUGA, Cláudio; BRANDÃO, Gildo M. (Orgs.). Clássicos do pensamento político. São Paulo: EDUSP, 1998. LANGEVIN, Paul; WALLON, Henry. Plano de reforma LangevinWallon. In: MERANI, Alberto L. Psicologia e pedagogia: as ideias pedagógicas de Henri Wallon. Lisboa: Notícias, 1977. p. 175-221. LIMA, Elvira Souza. Ciclos de formação: uma reorganização do tempo escolar. São Paulo: Sobradinho 107, 2002.

LOCKE, John. Segundo tratado sobre o governo. In: Locke. São Paulo: Abril Cultural, 1983. (Coleção Os Pensadores)

MAINARDES, Jefferson. Reinterpretando os ciclos de aprendizagem. São Paulo: Cortez, 2007.

MARX, Karl. Trabalho assalariado e capital. In: MARX, Karl; ENGELS, Friendrich. Textos. v. 3. São Paulo: Ed. Sociais, s.d. MÉSZÁROS, István. Para além do capital. São Paulo: Boitempo; Campinas: Ed. da UNICAMP, 2002.

. O desafio e o fardo do tempo histórico. São Paulo: Boitempo, 2007.

MIRANDA, Marília G. Sobre tempos e espaços da escola: do princípio do conhecimento ao princípio da socialidade. Educação e Sociedade, Campinas, v. 26, n. 91, maio/ago. 2005.

.; RESENDE, Anita C.A. Eqüidade educativa e desigualdades sociais: retórica e exclusão. In: PEDROZA FLORES,
René; MASSÉ NARVÁES, Carlos (Orgs.). Educación y universidad desde la complejidad globalizada. México: Universidade Autônoma de México, 2009 (no prelo).

PERRENOUD, Philippe. Os ciclos de aprendizagem: um caminho para combater o fracasso escolar. Porto Alegre: Artmed, 2004.

RAWLS, John. Uma teoria da justiça. 2. ed. São Paulo: Martins Fontes, 2002.

ROUSSEAU, Jean J. Do contrato social. In: Rousseau. São Paulo: Abril Cultural, 1983a. (Coleção Os Pensadores.)

ROUSSEAU, Jean J. Discurso sobre a origem e os fundamentos da desigualdade entre os homens. In: Rousseau. São Paulo: Abril Cultural, 1983b. (Coleção Os Pensadores.)

TEIXEIRA, Edival S. A psicologia histórico-cultural como fundamento para a organização do ensino escolar em ciclos de aprendizagem. 2004. Tese (Doutorado) - Faculdade de Educação, Universidade de São Paulo, São Paulo, 2004.

TOCQUEVILlE, Aléxis. Democracia na América. São Paulo: Cia. Editora Nacional/USP, 1969.

WOOD, Ellen Meiksins. Democracia contra capitalismo: a renovação do materialismo histórico. São Paulo: Boitempo, 2003.

MARÍLIA GOUVEADE MIRANDA, doutora em educação pela Pontifícia Universidade de São Paulo (PUC-SP), é professora na Universidade Federal de Goiás (UFG). Integra, na Faculdade de Educação, o Núcleo de Estudos e Pesquisas em Psicologia, Educação e Cultura (NEPPEC), dedicando-se à pesquisa de temas relacionados à racionalidade no campo educacional, com ênfase nos fundamentos da educação, em particular a psicologia da educação. Publicações recentes: “A psicologia da educação na perspectiva da relação entre teoria e prática” (In: MIRANDA, Marília G.; RESENDE, Anita C. A. (Orgs.). Estudos de psicologia, educação e cultura. Goiânia: Ed. UCG, 2008); "Sobre tempos e espaços da escola: do princípio do conhecimento ao princípio da socialidade” (Educação e Sociedade, Campinas: CEDES, v. 27, n. 91, p. 639-651, maio/ ago. 2005); com RESENDE, Anita C. A. "Sobre a pesquisa-ação na educação e as armadilhas do praticismo” (Revista Brasileira de Educação, v. 11, n. 33, p. 511-518, set./dez. 2006). Pesquisa em andamento: “Equidade e educação: o eclipse da desigualdade”, com recursos do Conselho Nacional de Desenvolvimento Científico e Tecnológico (CNPq).E-mail: mgmiranda@uol.com.br

Recebido em novembro de 2008 Aprovado em dezembro de 2008 